\title{
ARAHAN PERENCANAAN INFRASTRUKTUR LINGKUNGAN DI KAWASAN WISATA JUNGKAT BEACH, DESA JUNGKAT, KECAMATAN SIANTAN, KABUPATEN PONTIANAK, KALIMANTAN BARAT
}

\author{
Rachmanto Wibowo ${ }^{-1}$, Winardi Yusuf S.T, M.T ${ }^{-1}$, Hj. Mira Sophia Lubis S.T, M.T ${ }^{-2}$ \\ ${ }^{1}$ Program Studi Teknik Lingkungan, Universitas Tanjungpura, Pontianak \\ ${ }^{2}$ Program Studi Perencanaan Wilayah dan Tata Kota, Universitas Tanjungpura, Pontianak \\ Email : letter_in_summer@yahoo.co.id
}

\begin{abstract}
ABSTRAK
Jungkat Beach adalah salah satu jenis wisata pantai yang terletak di Desa Jungkat, Kecamatan Siantan, Kabupaten Pontianak yang telah beroperasi dari tahun 2007 hingga sekarang. Pada kawasan wisata Jungkat Beach terdapat berbagai masalah yang timbul akibat infrastruktur lingkungan yang kurang baik yang dapat mengganggu keberlangsungan kegiatan wisata dan lingkungan, sehingga diperlukannya perencanaan infrastruktur lingkungan di kawasan wisata Jungkat Beach. Penelitian ini menggabungkan konsep perencanaan berkelanjutan untuk empat infrastruktur lingkungan yang diaplikasikan dalam kawasan komersil yaitu kawasan wisata. Tujuan dari penelitian ini yaitu membuat arahan perencanaan infrastruktur lingkungan di kawasan wisata Jungkat Beach, yang meliputi (a) Infrastruktur Air Bersih, (b) Infrastruktur Air Limbah, (c) Infrastruktur Persampahan, (d) Infrastruktur Drainase.
\end{abstract}

Penelitian ini menggunakan metode analisa yang umum digunakan dalam merencanakan infrastruktur di suatu kawasan. Luaran yang dihasilkan berupa data perhitungan dan gambar desain. Alat bantu yang digunakan dalam penelitian ini yaitu AutoCAD 2010, EPANET ver 2.0, dan GPS. Kesimpulan yang dihasilkan yaitu: (a) Air bersih bersumber dari air permukaan yaitu kolam. Kebutuhan air bersih kawasan adalah 69.941 liter/hari. Dialirkan menggunakan bantuan pompa dengan head 9 meter dan debit 100 I/m untuk mengaliri air ke semua fasilitas. Pipa yang digunakan untuk mendistribusikan air ke fasilitas penginapan adalah PVC 1,5 inch, fasilitas restoran adalah PVC 2 inch, dan fasilitas kantin adalah PVC 1 inch. Diameter pipa transmisi adalah pipa PVC 2,5 inch. (b) Air limbah yang disalurkan berasal dari kegiatan domestik. Debit rencana air limbah adalah 60.162 liter/hari. Air limbah dialirkan menggunakan sistem gravitasi. Jenis pipa yang digunakan adalah pipa PVC 1,5 inch untuk jaringan S1, pipa PVC 2 inch untuk jaringan S2, pipa PVC 1 inch untuk jaringan S3, pipa PVC 2,5 inch untuk jaringan S4, pipa PVC 3 inch untuk jaringan S5. (c) Timbulan sampah pada tahun 2023 adalah 1,23 m3/hari. Bahan yang digunakan untuk wadah komunal dan TPS adalah HDPE. Jumlah wadah komunal di sekitar lokasi wisata 12 unit ukuran 60 liter, kantin 8 unit ukuran 50 liter, restoran 6 unit ukuran 60 liter dan hotel 4 unit ukuran 25 liter. Jumlah wadah pada TPS sebanyak 2 unit ukuran 700 liter. Sampah organik yang dihasilkan dibuat pupuk kompos dan sampah anorganik dijual ke pengumpul atau pengrajin barang bekas. (d) Infrastruktur drainase yang direncanakan menggunakan saluran terbuka berbentuk segiempat di alirkan secara gravitasi. Pada bagian atas saluran diberi Gratting Stell. Dimensi saluran pada daerah I (tersier) memiliki $\mathrm{h}=0,40 \mathrm{~m}$ dan $\mathrm{b}=0,64 \mathrm{~m}$, daerah II (tersier) memiliki $\mathrm{h}=0,34 \mathrm{~m}$ dan $\mathrm{b}=0,54 \mathrm{~m}$, daerah III (sekunder) memiliki $\mathrm{h}=0,55 \mathrm{~m}$ dan $\mathrm{b}=0,88 \mathrm{~m}$, sedangkan daerah IV (primer) memiliki $\mathrm{h}=$ $0,62 \mathrm{~m}$ dan $\mathrm{b}=0,99 \mathrm{~m}$.

Kata Kunci: Infrastruktur Lingkungan, Infrastruktur Wisata, Wisata Pantai.

\begin{abstract}
Jungkat Beach is one kind of tourism that located on Jungkat Village, Siantan District, Pontianak Regency, which has been operated from 2007 until now. In Jungkat Beach there are many problems that arise as a result of poor environmental infrastructure that can disturb tourism activities and environmental sustainability, so that the location need environmental infrastructure planning. This research combining sustainable planning concept for four kind of environmental infrastructure that applied on commercial area that is tourism area. Purpose of this research are to make referrals
\end{abstract}


environmental infrastructure planning in Jungkat Beach area, that includes of (a) Clean Water Infrastructure, (b) Waste Water Infrastructure, (c) Garbage Infrastructure, (d) Drainage Infrastructure.

This research uses analytical methods that commonly used in the planning of infrastructure in some areas. Outcomes produced in the form of data calculation and design drawings. The tools used in this research are AutoCAD 2010, EPANET ver 2.0, and GPS. The result are: (a) the clean water sourced from surface water that is pools. This research uses analytical methods that commonly used in the planning of infrastructure in a area. Outcomes produced in the form of data calculation and design drawings. The tools used in this research are AutoCAD 2010, EPANET ver 2.0, and GPS. The result are: (a) The clean water sourced from surface water that is pools. The needs of clean water of the area is 69.941 liters / day. Flowed using pump with head 9 meters and debit head $100 \mathrm{I} / \mathrm{m}$ to flow water through all facilities. Pipe used to distribute water to the inn facility is 1,5 inch PVC pipe, restaurant facility is 2 inches PVC pipe, and canteen facility are 1 inch PVC pipe. Transmission pipe diameter is 2,5 inch PVC pipe. (b) The waste water is channeled coming from domestic activities. Wastewater debit plan is 60.162 liters / day. Waste water channeled using gravity system. Type of pipe used is 1,5 inch PVC pipe for S1, 2 inch PVC pipe for S2, 1 inch PVC pipe for the S3, 2,5 inch PVC pipe for S4, 3-inch PVC pipe for S5. (c) Garbage generation in 2023 was $1.23 \mathrm{~m}^{3} /$ day. Materials used for communal containers and the polling station is HDPE. The number of communal containers around the tourist area are 12 units of 60 liters, canteen 8 unit of 50 liters, restaurant 6 unit of 60 liters and hotel 4 units of 25 liters. The number of containers at the polling station 2 unit of 700 liters. Organic garbage will be composted and inorganic garbage sold to collectors or junk craftsmen. (d) The planned drainage infrastructure uses a rectangular shaped open channel flowed by gravity system. At the top of the channel is given Gratting Stell. Dimensional channel in area I (tertiary) has $h=0,40 \mathrm{~m}$ and $b=0,64 \mathrm{~m}$, area II (tertiary) has $h=0,34 \mathrm{~m}$ and $b=0,54 \mathrm{~m}$, area III (secondary) has $h=0,55 \mathrm{~m}$ and $b=0,88 \mathrm{~m}$, while the region $\mathrm{IV}$ (primary) has $h=0,62 \mathrm{~m}$ and $b=0,99 \mathrm{~m}$.

Keywords : Environmental Infrastructure, Tourism Infrastructure, Tourism Beach.

\section{Latar Belakang}

Pariwisata merupakan sektor yang sangat kompleks karena pariwisata bersifat multidimensi, baik fisik, sosial budaya, ekonomi, dan politik. Selain itu kegiatan pariwisata akan melibatkan berbagai sektor dan lembaga yang terkait. Berkembangnya sektor pariwisata di suatu negara akan menarik sektor lain untuk berkembang juga, karena produk-produknya diperlukan untuk menunjang pariwisata itu sendiri, seperti sektor pertanian, peternakan, perkebunan, kerajinan rakyat, peningkatan kesempatan kerja, dan lain sebagainya.

Manfaat infrastruktur lingkungan pada kawasan wisata adalah menjaga stabilitas lokasi wisata terhadap kegiatan manusia dan gejala alam, seperti infrastruktur drainase yang berfungsi sebagai saluran yang mengalirkan air limpasan akibat hujan menuju ke saluran yang lebih besar agar tidak menggenangi lokasi wisata.

Penelitian ini menggabungkan konsep perencanaan berkelanjutan untuk empat infrastruktur lingkungan yang diaplikasikan dalam kawasan komersil yaitu kawasan wisata. Tujuan dari penelitian ini yaitu membuat arahan perencanaan infrastruktur lingkungan di kawasan wisata Jungkat Beach untuk jangka waktu 10 tahun ke depan, yang meliputi Infrastruktur Air Bersih, Infrastruktur Air Limbah, Infrastruktur Persampahan dan Infrastruktur Drainase. Metode analisa yang digunakan adalah metode yang umum digunakan dalam merencanakan infrastruktur di suatu kawasan.

\section{Metode Penelitian}

a. Lokasi Penelitian

Lokasi penelitian yaitu Jungkat Beach yang terletak di Desa Jungkat, Kecamatan Siantan, Kabupaten Pontianak. Berjarak kurang lebih 19 km dari Kota Pontianak. Letaknya berada tepat di kuala muara Sungai Kapuas. 


\section{b. Jenis Data}

Jenis data yang digunakan dalam penelitian ini adalah data primer dan data sekunder. Data primer diperoleh secara langsung dari sumber data sedangkan data sekunder didapat diperoleh dari berbagai instansi pemerintah maupun swasta.

Data primer yang digunakan yaitu lain data elevasi atau kemiringan lahan dan data kondisi pewadahan sampah, sedangkan data sekunder yang digunakan yaitu data jumlah pengunjung dan pengelola, denah lokasi penelitian dan data curah hujan.

c. Teknik Pengumpulan Data

Teknik pengumpulan data yang akan digunakan adalah sebagai berikut:

- Penelitian Lapangan

\section{1) Survei / Pengamatan}

Survei / Pengamatan yang akan dilakukan yaitu melakukan survei lapangan tentang kondisi eksisting infrastruktur lingkungan yang ada, melakukan pengukuran elevasi/kemiringan lahan untuk kebutuhan perencanaan penyaluran air bersih, air limbah dan air limpasan (drainase), meninjau tempat pewadahan sampah yang tersedia.

2) Wawancara

Wawancara akan dilakukan kepada instansi terkait yaitu BAPPEDA Kabupaten Mempawah, Dinas Pariwisata Kabupaten Mempawah, Dinas Pekerjaan Umum Kabupaten Mempawah, Dinas Kebersihan Kabupaten Mempawah, Pihak Swasta Pengelola Wisata.

- Studi kepustakaan

Teknik pengumpulan data dengan mempelajari, membaca, dan mencatat buku-buku, literatur peraturan perundang-undangan yang diperlukan dalam perencanaan.

d. Analisa Data

Pada analisis data nantinya akan digunakan beberapa alat bantu yang berupa software (perangkat lunak) dan hardware (perangat keras). Software yang akan digunakan adalah AutoCAD versi 2010 dan EPANET versi 2.0. Sedangkan hardware yang akan digunakan dalam pengukuran elevasi adalah GPS (Global Positioning System).

\section{Hasil dan Pembahasan}

a. Proyeksi Pertambahan Penunjung

Analisis proyeksi pertambahan pengunjung merupakan langkah awal yang dilakukan dalam perencanaan agar dapat menentukan secara teori jumlah pengunjung wisata beberapa tahun ke depan. Dalam perencanaan ini akan digunakan metode Aritmatik, Geometri dan Exponensial untuk menentukan jumlah pengunjung pada 10 tahun yang akan datang. Data jumlah pengunjung dari tahun 2007 hingga 2013 dapat dilihat pada tabel di bawah ini :

Tabel 1. Persentase Pertambahan Pengunjung

\begin{tabular}{|c|c|c|c|}
\hline \multirow{2}{*}{ Tadnun } & \multirow{2}{*}{$\begin{array}{c}\text { Pengunjung } \\
\text { Makaimim Per Hari }\end{array}$} & \multicolumn{2}{|c|}{ Pertambahan Pengunjung } \\
\hline & & (coring) & (persma) \\
\hline 2007 & 157 & $=$ & $*$ \\
\hline 2008 & 178 & 21 & $13.38 \% 6$ \\
\hline 2000 & 203 & 27 & $15.17 \%$ \\
\hline 2010 & 226 & 31 & $15.12 \%$ \\
\hline 2011 & 104 & -42 & $-17.80 \%$ \\
\hline 2012 & 100 & -5 & $-258 \% 6$ \\
\hline 2013 & its. & -4 & $-212 \%$ \\
\hline \multicolumn{3}{|c|}{ Rasio } & 3.52946 \\
\hline
\end{tabular}

Dari hasil analisa persentasi pertambahan pengunjung didapatkan nilai Rasio yaitu 3,529\%. Berikutnya nilai Rasio ini akan digunakan dalam menganalisis pertambahan pengunjung dari tahun 2014 hingga 2023 menggunakan metode Aritmatik, Geometri dan Exponensial. Hasil analisis dapat dilihat pada tabel di bawah ini : 
Tabel 2. Proyeksi Pengunjung Tahun 2014 - 2023 Berbagai Metode

\begin{tabular}{|c|c|c|c|}
\hline \multirow{2}{*}{ Then } & \multicolumn{3}{|c|}{ Rerntehn Propoum! } \\
\hline & Nien & Genien & Expons \\
\hline 2014 & wi2 & in & in \\
\hline zois & iच & 16 & as \\
\hline zots & ass & s: & in \\
\hline an? & 24 & as & 162 \\
\hline 3011 & 216 & $m$ & 103 \\
\hline 2010 & 234 & ma & $\pm w$ \\
\hline 2005 & 29 & 26 & 202 \\
\hline 2021 & a? & 244 & see \\
\hline 2022 & 24 & as & 300 \\
\hline 3025 & 250 & 2e: & 212 \\
\hline Kotelas: & $0 x$ & Ex & 06 \\
\hline
\end{tabular}

Pertambahan pengunjung yang nilai korelasi metode paling mendekati 1 akan digunakan sebagai acuan dalam perencanaan (Kimsan, 2007). Dari tabel di atas diketahui nilai korelasi yang paling mendekati 1 adalah metode Geometri dengan faktor korelasi 0,82.

b. Arahan Perencanaan Infrastruktur Air Bersih

Dalam membuat arahan rencana infrastruktur air bersih dilakukan pertama kali adalah menganalisa jumlah kebutuhan air bersih sektor fasilitas umum (non-domestik) dan kebutuhan air bersih sektor domestik. Di bawah ini merupakan hasil analisa kebutuhan air bersih setiap sektor dan total kebutuhan semua sektor sesuai dengan Kriteria Perencanaan Ditjen Cipta Karya Dinas PU tahun 1996 :

Tabel 3. Kebutuhan Air Bersih Setiap Sektor Wisata Jungkat Beach

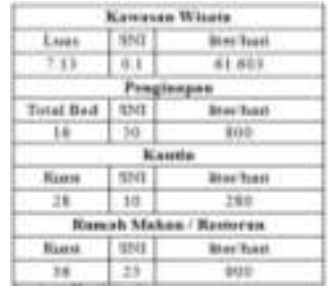

Tabel 4. Kebutuhan Air Bersih Semua Sektor Wisata Jungkat Beach

\begin{tabular}{|l|r|r|r|}
\hline \multicolumn{1}{|c|}{ Sektor } & \multicolumn{1}{c|}{$\begin{array}{c}\text { Qd } \\
\text { (liter/har) }\end{array}$} & $\begin{array}{c}\text { Qo } \\
\text { (liter/har) }\end{array}$ & $\begin{array}{c}\text { IQd } \\
\text { (liter/hari) }\end{array}$ \\
\hline Domestik & 61.603 & $6.160,32$ & $67.763,52$ \\
\hline Penginapan & 800 & 80,00 & 880,00 \\
\hline RumahMakan/Restoran & 900 & 90,00 & 990,00 \\
\hline Kantin & 280 & 28,00 & 308,00 \\
\hline \multicolumn{3}{|l|}{ Jumlah } & $\mathbf{6 9 . 9 4 1 , 5 2}$ \\
\hline
\end{tabular}

Dalam sebuah perencanaan infrastruktur air bersih, dimensi pipa distribusi wajib dihitung sesuai dengan debit kebutuhan fasilitas umum pada hari puncak.

Tabel 5. Debit Air Bersih Dalam Pipa Setiap Sektor

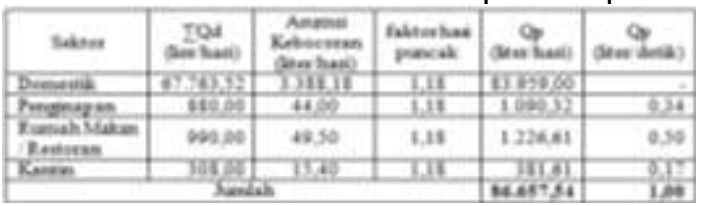

Jenis pipa yang digunakan adalah PVC tipe AW karena paling tebal dan cocok untuk aliran bertekanan. Besarnya dimensi pipa yang sesuai untuk menyalurkan air bersih ke setiap fasilitas umum yang ada di kawasan wisata Jungkat Beach dan pipa transmisi untuk menyalurkan air bersih dari sumber ke pipa distribusi adalah sebagai berikut :

Tabel 6. Dimensi Pipa Distribusi

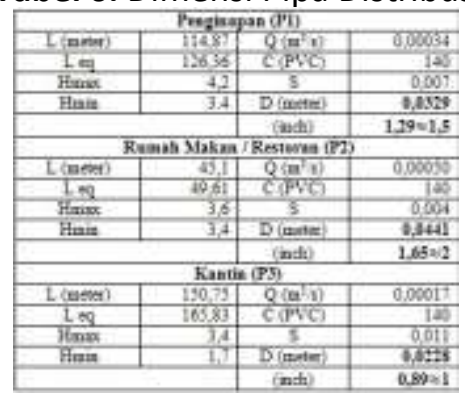

Tabel 7. Debit Kebutuhan Air Bersih Jungkat Beach Tahun 2023

\begin{tabular}{|c|c|c|c|}
\hline \multicolumn{4}{|c|}{ T (Transmisi) } \\
\hline$L$ (meter) & 15 & $Q\left(\mathrm{~m}^{2} / \mathrm{s}\right)$ & 0,001 \\
\hline Leq & 16.5 & $c(P \vee C)$ & 140 \\
\hline Himax & 3.4 & 5 & 0,006 \\
\hline Hmin & 3,3 & $D$ (meter) & 0,0513 \\
\hline & & (inch) & $2,02 \approx 2,5$ \\
\hline
\end{tabular}


Seletelah dimensi setiap jaringan pipa didapatkan, berikutnya adalah melakukan simulasi pengaliran air bersih dengan bantuan program EPANET 2.0

Tabel 8. Hasil Uji Pengaliran

Dengan EPANET 2.0

\begin{tabular}{|c|c|c|c|c|c|c|}
\hline Link ID & $\begin{array}{l}\text { Length } \\
\text { (mi) }\end{array}$ & $\begin{array}{l}\text { Dhameter } \\
\text { (Exh) }\end{array}$ & Reufnesu & $\begin{array}{l}\text { Velocity } \\
\text { (imin) }\end{array}$ & $\begin{array}{l}\text { Tresume } \\
\text { (m) }\end{array}$ & Seatur \\
\hline Pipe 1 & 2427 & 1 & 140 & 0.37 & 292 & Open \\
\hline Prpe? & 4495 & 1 & 140 & 037 & 314 & Open \\
\hline Pepe 3 & 33.87 & $t$ & 140 & ह39 & 345 & Open \\
\hline Pept 4 & 27.77 & 1 & 140 & 0.37 & 3,7 & open \\
\hline Ppes 5 & 1130 & 2 & 140 & 0.28 & 280 & open \\
\hline Plpe 6 & 63.66 & 15 & 140 & 0.67 & 161 & Open \\
\hline Pipe T & 5121 & is & 140 & 0.33 & 100 & Open \\
\hline Pept 8 & 1992 & 1 & 140 & 037 & 305 & Open \\
\hline Fpe 9 & 1500 & 25 & 140 & 04 & 310 & Open \\
\hline Aipe 10 & 33.80 & 2 & 140 & 0.28 & 312 & Open \\
\hline Pump X & $\equiv \mathrm{NA}$ & $\mathrm{DNA}$ & $=\mathrm{NA}$ & 0.00 & 669 & Open \\
\hline
\end{tabular}

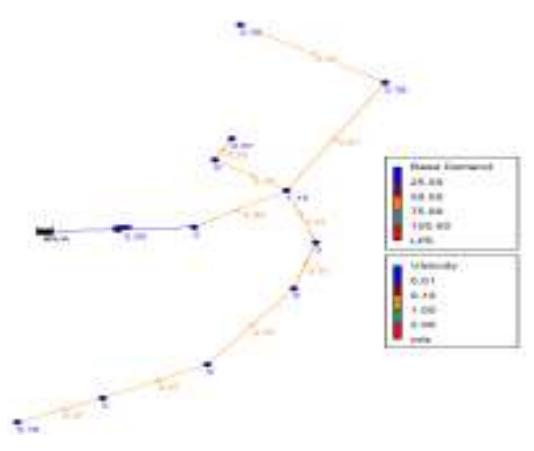

Gambar 1. Simulasi Pengaliran Air Bersih Dengan EPANET 2.0

Dalam proses simulasi didapatkan bahwa spesifikasi pompa paling minimum memiliki head $\geq 8$ meter dan debit $\geq 1,5$ liter/detik. Jenis pompa yang dipilih harus jenis pompa otomatis agar air bisa disalurkan kapan saja saat dibutuhkan. Maka dipilih pompa merk Interdab DB 175 A yang mempunyai spesifikasi head 9 meter dan debit 100 liter/menit.

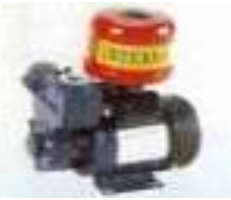

Gambar 2. Pompa Interdab DB 175 A

c. Arahan Perencanaan Infrastruktur Air Limbah

Dalam pembuatan arahan perencanaan infrastruktur air limbah di kawasan wisata Jungkat Beach hanya akan menyalurkan air limbah hasil kegiatan domestik dari fasilitas umum penginapan, kantin dan rumah makan/restoran. Standar yang digunakan adalah standar yang dibuat oleh Badan Pengkajian dan Penerapan Teknologi (BPPT) tahun 2010.

Tabel 9. Debit Air Limbah Jungkat Beach Tahun 2023

\begin{tabular}{|l|c|c|c|}
\hline \multicolumn{1}{|c|}{ Peruntukan } & $\begin{array}{c}\text { Q Aix Bersih } \\
\left(\mathrm{m}^{2} / \mathrm{s}\right)\end{array}$ & $\begin{array}{c}\text { Standax } \\
\%\end{array}$ & $\begin{array}{c}\text { Q Air Limbah } \\
\left(\mathrm{m}^{2 / 3}\right)\end{array}$ \\
\hline Kawasan Wisata & 61,603 & $80 \%$ & 49,283 \\
\hline Penginapan & 800 & $80 \%$ & 640 \\
\hline Kantin & 280 & $90 \%$ & 252 \\
\hline $\begin{array}{l}\text { RumahMakan } \\
\text { Reatoran }\end{array}$ & 900 & $90 \%$ & 810 \\
\hline
\end{tabular}

Setelah didapatkan debit limbah yang dihasilkan setiap fasilitas umum, selanjutnya akan dihitung debit rencana yang akan digunakan dalam menghitung dimensi pipa yang cocok untuk menyalurkan air limbah.

Tabel 10. Debit Rencana Air Limbah Jungkat Beach

\begin{tabular}{|l|c|c|c|c|}
\hline \multicolumn{1}{|c|}{ Jenis } & $\begin{array}{c}\text { Debit } \\
\text { (liter han) }\end{array}$ & FP & $\begin{array}{c}\text { Debit Rencana } \\
\text { (iter han) }\end{array}$ & $\begin{array}{c}\text { Debit Rencana } \\
\text { (liter/detik) }\end{array}$ \\
\hline Penginapan & 640 & 1,18 & $\mathbf{7 5 5}$ & $\mathbf{0 , 2 3}$ \\
\hline Kantin & 252 & 1,18 & $\mathbf{2 9 7}$ & $\mathbf{0 , 1 2}$ \\
\hline RumahMakan & 810 & 1,18 & 956 & $\mathbf{0 , 3 5}$ \\
\hline Kawasan Wisata & 49.283 & 1,18 & $\mathbf{5 8 . 1 5 3}$ & $\cdot$ \\
\hline \multicolumn{2}{|r|}{ Jumlah } & $\mathbf{6 0 , 1 6 2}$ & $\mathbf{0 , 7}$ \\
\hline
\end{tabular}

Faktor puncak yang digunakan sana debgab faktor puncak pada perencanaan infrastruktur air bersih yaitu 1,18 . Setelah didapatkan nilai debit rencana, selanjutnya adalah menentukan diameter atau dimensi pipa penyaluran air limbah. Dalam penentuan dimensi yang sesuai dan efisien dilakukan metode uji coba benar atau salah dengan memvariasikan kecepatan aliran air limbah dengan menggunakan persamaan Manning. Hal yang harus diperhatikan adalah kecepatan aliran 0,3 - 3 meter/detik, nilai $\mathrm{Fr}<1$ dan nilai Qpipa > Qrencana (Larasati, 2014). 
Tabel 11. Hasil Uji Kecepatan Aliran Untuk Dimensi Pipa Air Limbah

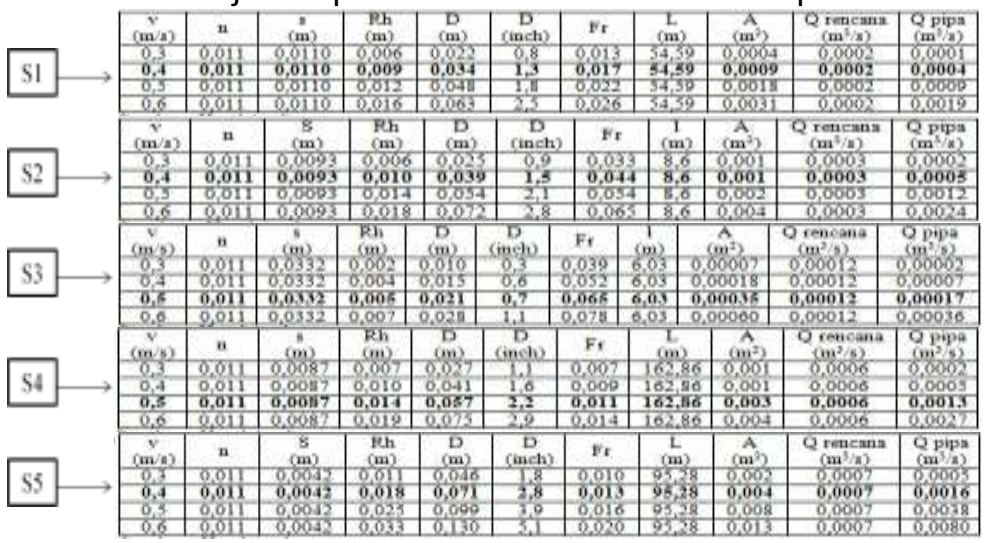

Untuk jenis pipa yang digunakan adalah pipa PVC tipe D karena umum digunakan untuk penyaluran air buangan secara gravitasi. Berikut adalah ukuran pipa yang digunakan dalam perencanaan penyaluran air limbah sesuai dengan ukuran yang dijual di pasaran.

Tabel 12. Dimensi Pipa Penyaluran Air Limbah Masing-Masing Jaringan

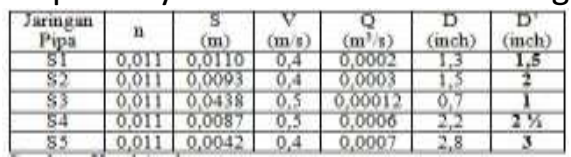

Dan di bawah ini merupakan jaringan pipa instalasi air limbah pada kawasan perencanaan :

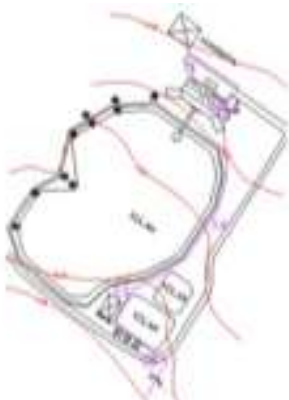

Gambar 3. Jaringan Pipa Penyaluran Air Limbah Kawasan Wisata Jungkat Beach

\section{d. Arahan Perencanaan Infrastruktur Persampahan}

Dalam pembuatan arahan perencanaan infrastruktur persampahan dihitung terlebih dahulu jumlah timbulan sampah per hari di kawasan Wisata Jungkat Beach pada tahun 2023. Berikutnya adalah menentukan jumlah dan ukuran tempat sampah serta ukuran tempat pembuangan sementara (TPS) pada kawasan wisata.

Tabel 13. Jumlah Timbulan Sampah Jungkat Beach Tahun 2023

\begin{tabular}{|c|c|c|}
\hline \multicolumn{3}{|c|}{ Kawasan Wisata } \\
\hline Pengunjung & $\begin{array}{l}\text { SNI } \\
\text { (diter) }\end{array}$ & $\begin{array}{l}\text { Timbulan } \\
\left(m^{3} / \text { hani }\right)\end{array}$ \\
\hline 262 & 2.5 & 0.65 \\
\hline \multicolumn{3}{|c|}{ Toko/Kantin } \\
\hline Pengunjung & $\begin{array}{l}\text { SNI } \\
\text { (liter) }\end{array}$ & $\begin{array}{l}\text { Tmbulan } \\
\left(m^{\prime} / \text { han }\right)\end{array}$ \\
\hline 183 & 1.75 & 0.32 \\
\hline \multicolumn{3}{|c|}{ Restoran } \\
\hline Pengunjung & $\begin{array}{l}\text { SNI } \\
\text { (liter) }\end{array}$ & $\begin{array}{l}\text { Timbulan } \\
\left(\mathrm{m}^{3} / \mathrm{han}\right)\end{array}$ \\
\hline 105 & 2 & 0.21 \\
\hline \multicolumn{3}{|c|}{ Penginapan } \\
\hline Bed & $\begin{array}{l}\text { SNI } \\
\text { Giten }\end{array}$ & $\begin{array}{l}\text { Timbulan } \\
\left(\mathrm{m}^{3} / \mathrm{han}\right)\end{array}$ \\
\hline 16 & 3 & 0.05 \\
\hline
\end{tabular}

Tabel 14. Ukuran Wadah Sampah

Berbagai Jenis Peruntukan

\begin{tabular}{|l|c|c|c|}
\hline \multicolumn{1}{|c|}{ Peruntukan } & $\begin{array}{c}\text { Timbulan Sampah } \\
\left(\mathrm{m}^{5} \text { han }\right)\end{array}$ & Jumlah Wadah & $\begin{array}{c}\text { Ukuran Wadah } \\
\left(\mathrm{m}^{2}\right)\end{array}$ \\
\hline Kawasan Panivisata & 0.65 & 6 & 0.109 \\
Toko Kantin & 0.32 & 4 & 0.080 \\
Restoran & 0.21 & 3 & 0.070 \\
Pengmapan & 0.05 & 2 & 0.024 \\
\hline \multicolumn{1}{|c|}{ IPS } & 1.23 & 1 & 1.23 \\
\hline
\end{tabular}


Pada arahan perencanaan infrastruktur persampahan akan dipilih sistem pewadahan terpisah antara anorganik dan organik. Hal ini dimaksudkan agar memudahkan menentukan sampah yang akan ditimbun dengan tanah (organik) dan didaur ulang (anorganik). Sehingga perlu ditentukan berapa ukuran ruang dalam wadah untuk sampah organik dan anorganik.

Tabel 15. Ukuran Ruang Dalam Wadah Sampah

\begin{tabular}{|c|c|c|c|c|c|c|}
\hline \multirow{2}{*}{ Peruntukan } & \multirow{2}{*}{$\begin{array}{l}\text { Ukuran Wadah } \\
\text { (liter) }\end{array}$} & \multirow{2}{*}{$\begin{array}{l}\text { Jumlah } \\
\text { Titik }\end{array}$} & \multirow{2}{*}{$\underset{(\%)}{\text { Organik }}$} & \multirow{2}{*}{$\begin{array}{c}\text { Anorganik } \\
(\%)\end{array}$} & \multicolumn{2}{|c|}{$\begin{array}{c}\text { Ukuran Ruang Dalam } \\
\text { Wadah }\end{array}$} \\
\hline & & & & & $\begin{array}{c}\text { Organik } \\
\text { (liter) }\end{array}$ & $\begin{array}{c}\text { Anorganik } \\
\text { (liter) }\end{array}$ \\
\hline Kawasan Pariwisata & 109 & 6 & $47 \%$ & $53 \%$ & 51 & 58 \\
\hline Toko/Kantin & 80 & 4 & $45 \%$ & $55 \%$ & 36 & 44 \\
\hline Restoran & 70 & 3 & $73 \%$ & $27 \%$ & 51 & 19 \\
\hline Hotel & 24 & 2 & $10 \%$ & $90 \%$ & 2 & 22 \\
\hline TPS & \multicolumn{2}{|l|}{1.232} & $44 \%$ & $56 \%$ & 539 & 693 \\
\hline
\end{tabular}

Sedangkan jenis bahan yang digunakan untuk pewadahan adalah berbahan HDPE. Karena wadah dengan bahan HDPE bersifat anti korosi, tidak mudah rusak, dan kedap air. Bahan yang sama juga akan diterapkan pada TPS, ini bertujuan agar mencegah sampah tersebut dibakar langsung di TPS.

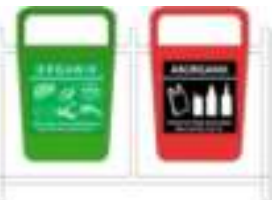

Gambar 4. Wadah Komunal

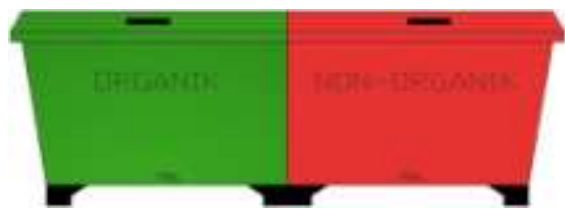

Gambar 5. Tempat Pembuangan Sementara

Untuk jalur pengangkutan sampah di kawasan Wisata Jungkat Beach dapat dilihat di bawah ini :

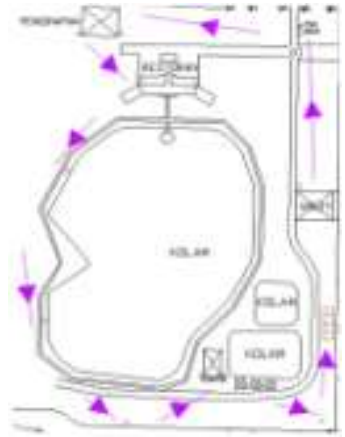

Gambar 6. Jalur Pengangkutan Sampah Di Kawasan Wisata Jungkat Beach

Dari hasil wawancara diketahui bahwa TPA (Tempat Pembuangan Akhir) yang ada di Kabupaten Mempawah masih menggunakan sistem Open Dumping, sehingga sampah akan dikelola langsung pada lokasi. Akan dibuat pondok kompos untuk mengelola sampah organik dan menjalin kerjasama dengan pengumpul barang bekas atau pengrajin untuk mengelola sampah anorganik.

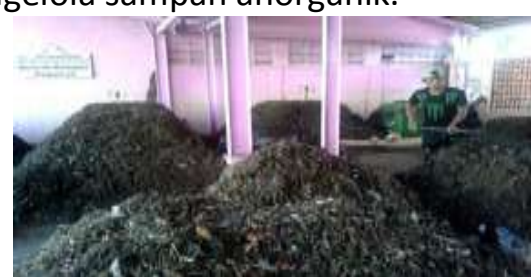

Gambar 7. Pondok Kompos

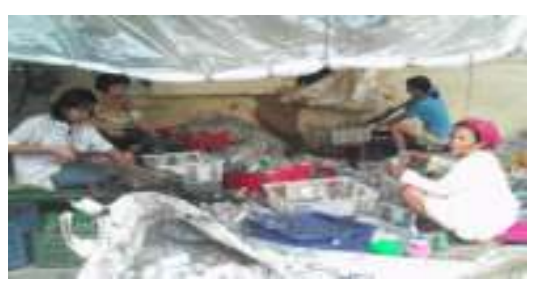

Gambar 8. Pengrajin Barang Bekas

e. Arahan Perencanaan Infrastruktur Drainase

Dalam membuat arahan perencanaan drainase di kawasan wisata Jungkat Beach, yang diperlukan sebagai data sekunder adalah data curah hujan, data curah hujan di ambil dari 
Stasiun Klimatologi Siantan. Berikut data curah hujan maksimum dari Stasiun Klimatologi Siantan.

Tabel 16. Data Curah Hujan Maksimum Stasiun Klimatologi Siantan

\begin{tabular}{|c|c|c|c|c|c|c|c|c|c|c|c|c|c|}
\hline TAHIX & JAN & FEB & MAR & APR & MIII & $\pi \mathrm{x}$ & $\pi \mathrm{L}$ & $A G S$ & SEP & OKI & XOP & DES & MAX \\
\hline 2004 & 36 & 9 & 62 & 49 & 129 & 49 & 99 & 3 & 103 & 8 & $5 t$ & 61 & 129 \\
\hline 2605 & 16 & $\$ 2$ & 34 & 31 & $\$ 0$ & 124 & 6 & 165 & 194 & Di & $\pi$ & 46 & 594 \\
\hline 2606 & 65 & 110 & 4 & 12 & 67 & 27 & 21 & 13 & 48 & $x$ & 93 & 121 & 121 \\
\hline 2607 & 97 & 20 & 45 & 35 & 75 & 99 & 57 & 30 & 153 & 68 & 68 & 78 & 150 \\
\hline 2605 & 58 & 16 & 71 & 63 & 124 & 95 & 57 & III & 53 & 151 & 99 & 97 & 181 \\
\hline 2009 & 191 & 19 & 40 & 104 & 23 & 98 & 11 & 160 & 38 & 50 & 121 & 74 & 121 \\
\hline 2010 & 30 & 70 & 39 & 41 & 42 & 79 & 117? & 45 & 103 & 33 & 110 & 66 & 187 \\
\hline 2611 & 40 & 19 & 37 & 141 & 70 & 41 & 60 & 49 & 53 & A1 & 91 & 72 & 141 \\
\hline 2612 & $4 \mathrm{t}$ & 24 & 19 & 76 & 107 & 25 & 54 & 40 & 24 & 49 & 49 & 62 & 169 \\
\hline 2013 & 34 & 49 & 24 & 108 & n & 41 & 68 & 86 & 35 & 30 & 106 & 87 & 105 \\
\hline
\end{tabular}

Setelah data curah hujan didapatkan, berikutnya adalah menganalisa data curah hujan tersebut untuk menentukan curah hujan rencana yang akan digunakan. Curah hujan rencana yang digunakan nantinya adalah hasil analisa dari metode distribusi kontinu yang memiliki nilai error paling kecil.

Tabel 17. Nilai \% Error Masing-Masing Metode Distribusi Kontinu

\begin{tabular}{|c|c|c|c|c|c|}
\hline \multirow{2}{*}{\multicolumn{2}{|c|}{ Hasil Perhitungan }} & \multicolumn{4}{|c|}{ Metode Distribusi Kontinu } \\
\hline & & \multirow{2}{*}{$\begin{array}{l}\text { Normal } \\
30.408 \\
\end{array}$} & \multirow{2}{*}{$\begin{array}{l}\text { Gumbel } \\
30.408\end{array}$} & \multirow{2}{*}{$\begin{array}{c}\text { Log } \\
\text { Pearson } \\
\text { Tipe III } \\
0.091 \\
\end{array}$} & \multirow{2}{*}{$\begin{array}{c}\begin{array}{c}\text { Log } \\
\text { Normal }\end{array} \\
0.091 \\
\end{array}$} \\
\hline 5 & 30.408 & & & & \\
\hline $\mathrm{C}_{3}$ & 0.725 & 0 & 1.139 & 0.438 & 0.127 \\
\hline $\mathrm{Ck}$ & .1 .208 & 3 & 5.402 & 1,488 & 3.029 \\
\hline $\mathrm{CV}_{\mathrm{V}}$ & 0.215 & 0.215 & 0.215 & 0.3 & 0.042 \\
\hline \multicolumn{2}{|c|}{ Enox } & $46.76 \%$ & $52.90 \%$ & $37.51 \%$ & $340.27 \%$ \\
\hline
\end{tabular}

Tabel 18. Analisa Curah Hujan Dengan

\begin{tabular}{|c|c|c|c|}
\hline Tahun & $\begin{array}{l}\text { Data Curah } \\
\text { Hujan }\end{array}$ & \multicolumn{2}{|c|}{$\log x$} \\
\hline 2004 & 129 & \multirow{2}{*}{\multicolumn{2}{|c|}{2.112}} \\
\hline 2005 & 194 & 2.288 & \\
\hline 2006 & 121 & \multicolumn{2}{|c|}{2.084} \\
\hline 2007 & 153 & \multicolumn{2}{|c|}{2.189} \\
\hline 2008 & 151 & \multicolumn{2}{|c|}{2.179} \\
\hline 2009 & 121 & \multicolumn{2}{|c|}{2.082} \\
\hline 2010 & 187 & \multicolumn{2}{|c|}{$2.27 \mathrm{t}$} \\
\hline 2011 & 141 & \multicolumn{2}{|c|}{2.150} \\
\hline 2012 & 107 & \multirow{2}{*}{\multicolumn{2}{|c|}{$\begin{array}{l}2.027 \\
2.034\end{array}$}} \\
\hline 2013 & 108 & & \\
\hline fumlah & 21.412 & $\mathrm{Cs}$ & 0.438 \\
\hline $\mathrm{n}$ & 10 & $k$ & 0.811 \\
\hline Rata rata & 2.1412 & $\log x$ & 2.215 \\
\hline $8 x$ & 0.0905 & $x$ & 163.91 \\
\hline
\end{tabular}

Dari data di atas diketahui bahwa curah hujan rencana yang akan digunakan dalam analisa berikutnya adalah sebesar $163,91 \mathrm{~mm}$. Selanjutnya menganalisa intensitas hujan yang bertujuan untuk mengetahui besarnya tinggi air hujan per satuan waktu. Data yang didapat akan dinyatakan dalam lengkung kurva IDF (Intensitas-Durasi-Frekuensi).

Tabel 19. Intensitas Huian

\begin{tabular}{|c|c|c|}
\hline Ment & $\begin{array}{l}\text { Durasi } \\
\text { (jail) }\end{array}$ & $\begin{array}{l}\text { Inteasian } \\
\text { (nmian) }\end{array}$ \\
\hline 5 & 808 & 297.54 \\
\hline 10 & 0.17 & 187,63 \\
\hline 15 & 0.25 & 143,19 \\
\hline 20 & 0.33 & 118,20 \\
\hline 25 & 0.42 & 101,86 \\
\hline 30 & 0.50 & 90,20 \\
\hline 35 & 0.58 & 81,39 \\
\hline 40 & 0.67 & 74,46 \\
\hline 45 & 0.75 & 68,84 \\
\hline 50 & 0.83 & 64.17 \\
\hline 55 & 0.92 & 60,22 \\
\hline 60 & 1.00 & 56,82 \\
\hline
\end{tabular}

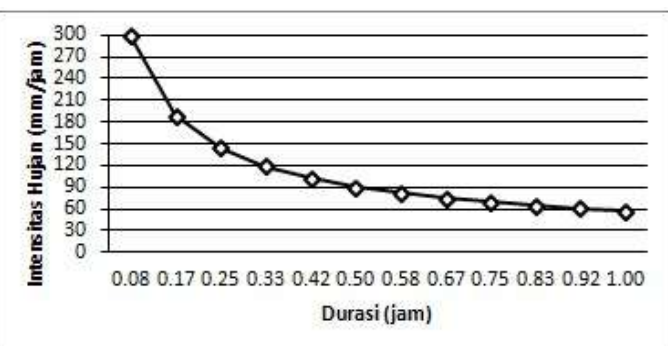

Gambar 9. Kurva Intensitas-Durasi-Frekuensi

Kurva di atas dapat dibaca, dalam frekuensi periode ulang 5 tahun sekali akan terjadi hujan berdurasi 0,67 jam dengan intensitas sebesar 74,46 mm/jam. Debit rencana dianalisa untuk mengetahui debit maksimum air limpasan yang di suatu kawasan. Data yang diperlukan adalah koefisien aliran setiap jenis penggunaan lahan, besar intensitas kawasan dan luas daerah tangkapan hujan. Untuk nilai $\mathrm{C}$ setiap daerah aliran dapat dilihat pada tabel di bawah ini : 


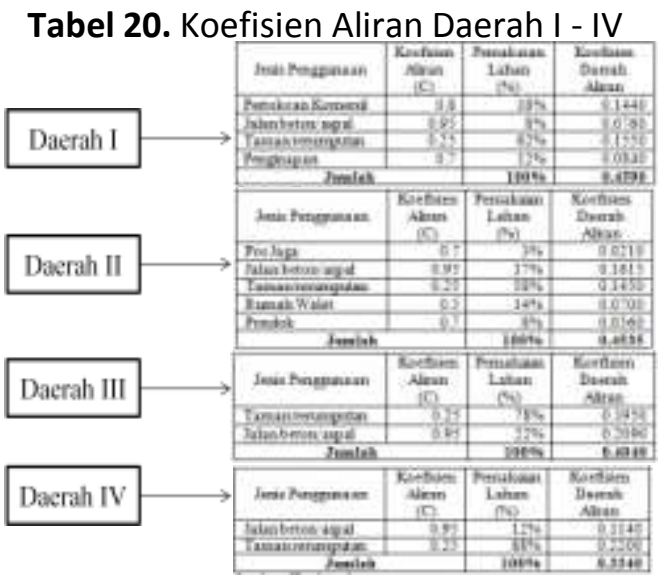

Setelah nilai koefisien daerah aliran telah didapatkan, berikutnya adalah menentukan besarnya debit rencana dengan persamaan rasional. Berikut adalah hasil analisa debit rencana untuk setiap daerah aliran :

Tabel 21. Debit Rencana Untuk Setiap Daerah Aliran Jugkat Beach

\begin{tabular}{|c|c|c|c|c|}
\hline Daerah & C & $\begin{array}{c}\text { I } \\
(\mathrm{mm} / \mathrm{jam})\end{array}$ & $\begin{array}{c}\mathrm{A} \\
\left(\mathrm{km}^{2}\right)\end{array}$ & $\begin{array}{c}\mathrm{Qp} \\
\left(\mathrm{m}^{3} / \mathrm{s}\right)\end{array}$ \\
\hline I & 0.4590 & 74,46 & 0.0159 & 0.156 \\
II & 0.4535 & 74,46 & 0.0068 & 0.066 \\
III & 0.4040 & 74,46 & 0.0429 & 0.488 \\
IV & 0.3340 & 74,46 & 0.0056 & 0.521 \\
\hline
\end{tabular}

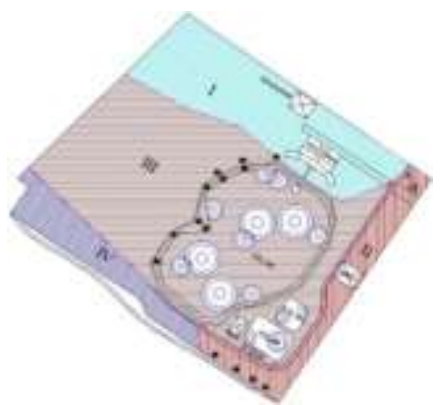

Gambar 10. Area Tangkapan Hujan

Dalam menentukan debit saluran hal yang harus diperhatikan adalah nilai Froud tidak boleh melebihi 1 , selain itu nilai dari debit saluran harus lebih besar dari debit rencana, serta kecepatan aliran untuk material beton harus berada di antara 0,4-3 m/s. Di bawah ini merupakan nilai debit saluran setiap daerah aliran :

Tabel 22. Debit Saluran Setiap

Daerah Jungkat Beach

\begin{tabular}{|c|c|c|c|c|c|c|c|c|c|c|c|c|}
\hline Dusted & $\begin{array}{c}9 \\
\left(m^{7}, n\right.\end{array}$ & $\underset{\text { im })}{b}$ & (m) & soo & $n$ & $\begin{array}{c}a \\
\mathbf{m}^{2}=\end{array}$ & A & ims & $\underset{\mathrm{R}}{\mathrm{R}}$ & iniv & F & $\begin{array}{l}\text { Janin } \\
\text { Alirn }\end{array}$ \\
\hline 1 & a.156 & 0.84 & 6.93 & 10602 & osts & 0.262 & 020 & 13 & 0.16 & 6.69 & 5.36 & $\begin{array}{l}\text { Sod } \\
\text { Kotith }\end{array}$ \\
\hline II & a.aes & 054 & 0.21 & {$[0.201$} & Q.Dts & 0.978 & 0.15 & 1.04 & 0.13 & $\Leftrightarrow 2$ & 0.31 & Som \\
\hline $\mathrm{mt}$ & Q.48a & oat & 0.44 & 0.001 & 6ots & a,73t & 0.10 & $\operatorname{lin}$ & 0.22 & 10 & 0.8 & Kat \\
\hline $\mathrm{N}$ & 0.521 & 0.95 & 0.48 & 0.002 & eas & 0.895 & 0.49 & 197 & 0.25 & 1.84 & 0.4 & $\begin{array}{l}\text { Sut } \\
\text { Kritio }\end{array}$ \\
\hline
\end{tabular}

Tabel 23. Dimensi Saluran Drainase Setiap Daerah Jungkat Beach

\begin{tabular}{|c|c|c|c|c}
\hline \multirow{2}{*}{ Daerah } & \multirow{2}{*}{$\begin{array}{c}\text { Qs } \\
\end{array}$} & \multicolumn{3}{|c}{ Dimensi Saluran } \\
\cline { 3 - 5 } & $\left(\mathrm{m}^{3 / \mathrm{s}}\right)$ & $\mathrm{w}(\mathrm{m})$ & $\mathrm{h}(\mathrm{m})$ & $\mathrm{b}(\mathrm{m})$ \\
\hline I & 0.202 & 0.08 & 0.40 & $0.64 \approx 0.7$ \\
\hline II & 0.076 & 0.07 & $0.34 \approx 0.4$ & $0.54 \approx 0.6$ \\
\hline III & 0.716 & 0.11 & $0.55 \approx 0.6$ & $0.88 \approx 0.9$ \\
\hline IV & 0.896 & 0.12 & $0.62 \approx 0.7$ & $0.99 \approx 1.0$ \\
\hline
\end{tabular}

Sebagai penutup drainase, akan digunakan penutup bahan plat besi anti karat yaitu Grating Steel. Alasan menggunakan penutup ini adalah karena memiliki bahan yang kuat, anti karat, dan mudah dipindahkan serta tetap dapat menjaga nilai estetika tanpa harus mengurangi fungsi drainase itu sendiri.

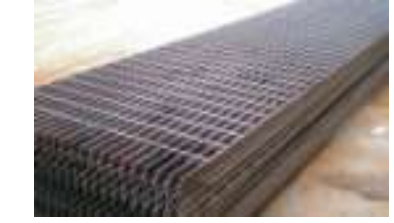

Gambar 11. Grating Steel

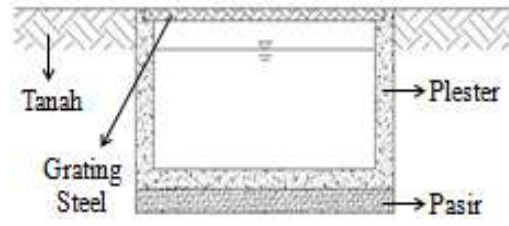

Gambar 12. Desain Drainase 


\section{Kesimpulan}

Dari hasil penelitian dan analisa, dapat disimpulkan bahwa arahan perencanaan infrastruktur lingkungan di kawasan wisata Jungkat Beach adalah sebagai berikut :

a. Air bersih bersumber dari air permukaan yaitu kolam. Kebutuhan air bersih kawasan adalah 69.941 liter/hari. Dialirkan menggunakan bantuan pompa dengan head 9 meter dan debit $100 \mathrm{l} / \mathrm{m}$ untuk mengaliri air ke semua fasilitas. Pipa yang digunakan untuk mendistribusikan air ke fasilitas penginapan adalah PVC 1,5 inch, fasilitas restoran adalah PVC 2 inch, dan fasilitas kantin adalah PVC 1 inch. Diameter pipa transmisi adalah pipa PVC 2,5 inch.

b. Air limbah yang disalurkan berasal dari kegiatan domestik. Debit rencana air limbah adalah 60.162 liter/hari. Air limbah dialirkan menggunakan sistem gravitasi. Jenis pipa yang digunakan adalah pipa PVC 1,5 inch untuk jaringan S1, pipa PVC 2 inch untuk jaringan S2, pipa PVC 1 inch untuk jaringan S3, pipa PVC 2,5 inch untuk jaringan S4, pipa PVC 3 inch untuk jaringan S5.

c. Timbulan sampah pada tahun 2023 adalah 1,23 m3/hari. Bahan yang digunakan untuk wadah komunal dan TPS adalah HDPE. Jumlah wadah komunal di sekitar lokasi wisata 12 unit ukuran 60 liter, kantin 8 unit ukuran 50 liter, restoran 6 unit ukuran 60 liter dan hotel 4 unit ukuran 25 liter. Jumlah wadah pada TPS sebanyak 2 unit ukuran 700 liter. Sampah organik yang dihasilkan dibuat pupuk kompos dan sampah anorganik dijual ke pengumpul atau pengrajin barang bekas.

d. Infrastruktur drainase yang direncanakan menggunakan saluran terbuka berbentuk segiempat di alirkan secara gravitasi. Pada bagian atas saluran diberi Gratting Stell. Dimensi saluran pada daerah I (tersier) memiliki $h=0,4 \mathrm{~m}$ dan $\mathrm{b}=0,7 \mathrm{~m}$, daerah II (tersier) memiliki $h=0,4 \mathrm{~m}$ dan $b=0,6 \mathrm{~m}$, daerah III (sekunder) memiliki $\mathrm{h}=0,6 \mathrm{~m}$ dan $\mathrm{b}=0,9 \mathrm{~m}$, sedangkan daerah IV (primer) memiliki $\mathrm{h}=0,7 \mathrm{~m}$ dan $\mathrm{b}=1,0 \mathrm{~m}$.

\section{Ucapan Terima Kasih}

Terima kasih yang sebesar-besarnya kepada kedua orang tua saya, Bapak Ir. Eddy Santoso dan Ibu Ria Puspita, S.Sos yang selalu mendoakan dan menyemangati saya hingga dapat menyelesaikan kuliah S-1 saya.

Kepada dosen-dosen pembimbing saya, Bapak Winardi Yusuf, S.T, M.T, dan Ibu Hj. Mira Sophia Lubis, S.T, M.T, yang selalu mengarahkan dan membantu dalam proses pembuatan tugas akhir ini. Serta kedua dosen penguji saya, Bapak H. Kiki Prio Utomo, S.T, M.Sc dan Ibu Dian Rahayu Jati, S.T, M.Si, terima kasih atas bimbingan dan ilmu yang diberikan, semoga dapat bermanfaat.

\section{Referensi}

Direktorat Jendral Cipta Karya Dinas Pekerjaan Umum. 1996. "Kriteria Perencanaan Sistem Penyaluran Air Bersih Perkotaan". Jakarta.

Badan Meteorologi Klimatologi Dan Geofisika. 2014. "Data Curah Hujan Maksimum Stasiun Klimatologi Siantan Tahun 2004-2013". Siantan.

Badan Pengkajian dan Penerapan Teknologi. 2010. "Buku Air Limbah Domestik". BAB X. Jakarta.

Kimsan, N Y. 2007. "Penentuan Kebutuhan Air Minum". Institut Teknologi Bandung. Bandung.

Larasati, D. 2014. "Perencanaan Sistem Penyaluran Air Buangan Pada Komplek Perumahan Grand Sukati Kecamatan Sungai Kakap Kabupaten Kubu Raya". Universitas Tanjungpura. Pontianak. 